\title{
Changes in the dynamics of Coxiella burnetii infection in dairy cattle: An approach to match field data with the epidemiological cycle of $C$. burnetii in endemic herds
}

\author{
A. Piñero, ${ }^{1}$ F. Ruiz-Fons, ${ }^{1,2}$ A. Hurtado, J. F. Barandika, R. Atxaerandio, and A. L. García-Pérez ${ }^{3}$ \\ NEIKER - Instituto Vasco de Investigación y Desarrollo Agrario, Department of Animal Health, Berreaga 1, 48160 Derio, Bizkaia, Spain
}

\begin{abstract}
This study aimed to evaluate changes in the epidemiological status of Coxiella burnetii in dairy cattle herds to better understand the epidemiology of the infection and to predict its evolution. Bulk-tank milk (BTM) and serum samples were collected from 94 dairy cattle herds and analyzed by ELISA (BTM and sera) and PCR (BTM) in study $1\left(\mathrm{~S}_{1}\right)$. Two years later (study $2 ; \mathrm{S}_{2}$ ), the same farms were visited with a similar sampling approach. To estimate seroconversion during this period, blood samples were collected from the maximum possible number of animals surveyed in $\mathrm{S}_{1}$. Environmental samples were collected in $\mathrm{S}_{2}$ to identify active shedding. Farms were allocated into 3 different categories in each study according to PCR and ELISA results: category A, with BTM ELISA and PCR positive herds and at least 1 seropositive animal; category B, with BTM ELISA or PCR positive herds or individual sera positive; and category $\mathrm{C}$, with all negative results among herds. Changes in herd category between $\mathrm{S}_{1}$ and $\mathrm{S}_{2}$ were grouped in 9 classes. Two statistical models, one to search for drives of within-herd changes in $C$. burnetii infection status and another to look for variables modulating individual changes in C. burnetii antibody level, were built. Several herds in category A in $\mathrm{S}_{1}$ remained in that category $2 \mathrm{yr}$ later, indicating that C. burnetii can remain within a herd for a long time. Most of the herds with seroconversion and detection of the bacterium in the environment belonged to category A, suggesting active and recent infections. Changes in the epidemiological status of herds were driven by local densities of domestic ruminants, showing the implication of neighbor reservoirs; whereas individual changes in antibody levels were modulated by variation in the epidemiological status of herds. Observed changes in
\end{abstract}

\footnotetext{
Received July 5, 2013.

Accepted January 22, 2014

${ }^{1}$ These authors contributed equally to this work.

${ }^{2}$ Present address: Animal Health and Biotechnology Group, Spanish National Wildlife Research Institute IREC, Ronda de Toledo s/n, 13171 Ciudad Real, Spain.

${ }^{3}$ Corresponding author: agarcia@neiker.net
}

epidemiological status allowed depiction of the hypothesized life cycle of $C$. burnetii within dairy cattle herds, which should be tested by future long-term series studies on $C$. burnetii infection to help fitting control measures (e.g., vaccination) to within-herd C. burnetii status.

Key words: Coxiella burnetii, dairy cattle, bulk-tank milk, epidemiology

\section{INTRODUCTION}

Coxiella burnetii is the causative agent of $\mathrm{Q}$ fever, a zoonotic disease in which domestic ruminants are considered the most important reservoirs and source for human infection (Woldehiwet, 2004). Clinical signs of Q fever in ruminants are diverse; $C$. burnetii has been associated with sporadic cases of abortion, premature delivery, stillbirth, and weak offspring in cattle, sheep, and goats, but epidemics associated to this complete expression of reproductive failure have only been reported for sheep and goats (Agerholm, 2013). Infected animals shed bacteria through vaginal fluids, birth products, feces, and milk, the latter being the main excretion route in cattle (Rodolakis et al., 2007). Inhalation of aerosols contaminated with extracellular forms of $C$. burnetii shed by infected animals is the main pathway of human and animal infection, especially when environmental conditions are favorable for the dispersion of bacteria (Tissot-Dupont et al., 1999, 2004; Evstigneeva et al., 2005; Hunink et al., 2010; van der Hoek et al., 2011).

$\mathrm{Q}$ fever is endemic in the Basque country (northern Spain). Recent studies have revealed the importance of sheep as the main source of the disease for humans (Cilla et al., 2008; García-Pérez et al., 2009), with beef cattle and goats as secondary reservoirs (Ruiz-Fons et al., 2010). Regarding dairy cattle, a recent study carried out in Bizkaia (Basque country, Spain) showed a widespread distribution of $C$. burnetii in the region (Astobiza et al., 2012). Thus, 66.9\% of the herds showed antibodies against $C$. burnetii in bulk-tank milk (BTM), and milk-shedding cows were detected in $51.7 \%$ of the herds, which, consequently, were BTM PCR positive. Similar studies have been made world- 
wide and, in general, most of them revealed a high prevalence of $C$. burnetii in dairy cattle farms (Kim et al., 2005; Agger et al., 2010; Muskens et al., 2011a). The occurrence of heavy-shedder cows, consisting of animals that shed high $C$. burnetii loads through different excretion routes for long periods and have high level of antibodies, is common in infected herds (Guatteo et al., 2007b, 2012), with a within-herd prevalence ranging between 18.0 and $85.0 \%$ (Guatteo et al., 2007a,b; Angen et al., 2011). These chronically infected animals maintain bacterial excretion and antibodies for several lactations, and this contributes to the positive BTM analyses by ELISA and PCR even though the active infection has been cleared. Monitoring positive farms by periodic sampling provides useful information on the current infection status in a farm; however, very few studies assess trends in $C$. burnetii epidemiology over time in dairy cattle farms (Angen et al., 2011; Paul et al., 2012). In a recent study (Piñero et al., 2012), 3 dairy herds with BTM samples positive to C. burnetii by ELISA and PCR were monitored, and, after $2 \mathrm{yr}$, infection was only active in one farm. Presence of $C$. burnetii DNA in slurry, aerosols, and dust from animal premises, as well as seroconversion in the group of heifers helped to identify an active and recent infection (Piñero et al., 2012). Following a similar approach, the objective of the current study was to evaluate the progression of $C$. burnetii infection in dairy cattle in a 2-yr period in an endemic region in northern Spain. During this period of time, different epidemiological scenarios could occur at farm level according to within-herd spread of $C$. burnetii, positive farms becoming negative, and vice versa among all possible intermediate stages (Paul et al., 2012). The observed within-herd changes in the epidemiological status of $C$. burnetii infection and the factors linked to these changes were used to predict a general pattern of temporal evolution of $C$. burnetii infection dynamics in dairy herds.

\section{MATERIALS AND METHODS}

\section{Selection of Dairy Cattle Herds and Sampling Approach}

A survey in 178 dairy cattle herds from Bizkaia (Basque country, northern Spain) was carried out between September 2009 and February 2010 [study 1 $\left(\mathbf{S}_{1}\right)$; Astobiza et al., 2012]. Briefly, a sample of BTM and blood samples from 15 animals (5 calves older than 6 mo, 5 heifers 1-2 yr old, and 5 cows older than 2 yr) were taken from each herd and analyzed by ELISA (BTM and blood) and PCR (BTM). Two years later [study $2\left(\mathbf{S}_{2}\right)$ ] 100 herds were preselected among the 178 herds previously investigated in $\mathrm{S}_{1}$. Selection was done on the basis of BTM results, aiming to choose $50 \%$ BTM-positive herds for both techniques (ELISA and PCR) and 50\% negative. Finally, sampling could be done in 94 herds between September 2011 and June 2012. A BTM sample $(100 \mathrm{~mL})$, blood samples (5 $\mathrm{mL}$ ) from 15 animals of different age categories, dust samples $(\mathrm{n}=5)$ from animal premises' surface, and a sample of slurry $(500 \mathrm{~mL}$ taken from the slurry tank after homogenization of its content) were collected from each herd. Thus, 308 calves, 334 heifers, and 688 cows were sampled in $\mathrm{S}_{1}$, whereas 19 calves, 324 heifers, and 1,023 cows were sampled in $\mathrm{S}_{2}$. To assess seroconversion rates in animals, blood samples were collected from the maximum number of animals previously sampled in $\mathrm{S}_{1}$ as possible $(\mathrm{n}=656)$. In addition, a small questionnaire was filled out to collect information concerning the size of the herd, current reproductive problems, vaccination implemented in the farms, presence of small ruminants in the herd, and so on.

Samples were collected by clinical veterinarians as part of the usual screening scheme on farms and Spanish ethical guidelines and animal welfare regulations (Spanish Royal Decree Law 1201/2005) were strictly respected. All herd owners had given an informed consent before the study.

\section{Serological Analyses}

Bulk-tank milk and blood (serum) samples were tested for the presence of antibodies against $C$. burnetii by a commercial indirect ELISA test according to manufacturer's instructions (LSIVET Ruminant Milk/ Serum Q Fever kit; Laboratoire Service International, Lissieu, France). The sample to positive control (S/P) ratio in individual serum samples was calculated as $\mathrm{S} / \mathrm{P}$ $=(\mathrm{OD}$ sample $-\mathrm{OD} \mathrm{NC}) /(\mathrm{OD} \mathrm{PC}-\mathrm{OD} \mathrm{NC})$, where OD sample = optical density of the sample; OD NC = optical density of the negative control; and OD PC = optical density of the positive control. The results were expressed as an index of $\mathrm{S} / \mathrm{P} \times 100$.

In the case of serum samples, sample-to-positive control ratio indices $\leq 40$ were considered negative, whereas indices $>40$ were indicative of positive serum. Conversely, BTM samples with $\mathrm{S} / \mathrm{P}$ indices $\leq 30$ were considered negative, whereas samples with indices $>30$ were considered positive for $C$. burnetii antibodies.

\section{Molecular Analyses}

Bulk-tank milk and dust samples (swabs taken from surfaces) were subjected to DNA extraction using the QIAmp DNA Blood Mini Kit (Qiagen, Valencia, CA). Briefly, $200 \mu \mathrm{L}$ of BTM mixed with $180 \mu \mathrm{L}$ of cell/ tissue lysis (ATL) buffer were digested with $20 \mu \mathrm{L}$ of 
proteinase $\mathrm{K}(8 \mathrm{mg} / \mathrm{mL})$ for $30 \mathrm{~min}$ at $70^{\circ} \mathrm{C}$. Swabs were placed in $300 \mu \mathrm{L}$ of Tris EDTA (TE) buffer (10 $\mathrm{m} M$ Tris Base, $1 \mathrm{~m} M$ EDTA, $\mathrm{pH} 8$ ), mixed with 180 $\mu \mathrm{L}$ of ATL, and digested with $20 \mu \mathrm{L}$ of proteinase $\mathrm{K}(8$ $\mathrm{mg} / \mathrm{mL}$ ) for $60 \mathrm{~min}$ at $55^{\circ} \mathrm{C}$.

Slurry samples $(0.3 \mathrm{~g})$ were added to $1 \mathrm{~mL}$ of PBS (Ambion, Life Technologies, Alcobendas, Madrid, Spain), vortexed for $3 \mathrm{~min}$, and centrifuged at $100 \times$ $g$ for $1 \mathrm{~min}$ at room temperature. Finally, $175 \mu \mathrm{L}$ of supernatant were subjected to DNA extraction using the MagMax Total Nucleic Acid Isolation Kit (Ambion, Life Technologies, Alcobendas, Madrid, Spain) following the manufacturer's instructions.

Negative extraction controls were included every 10 samples to rule out DNA contamination. The PCR was performed using primers targeting a transposon-like repetitive region of $C$. burnetii, as described elsewhere (Willems et al., 1994; Berri et al., 2000), adding a maximum of $70 \mathrm{ng}$ of DNA template to each reaction. The PCR positive control (Nine Mile strain) and PCR negative control (sterile water) were also included following standard procedures.

\section{Data Analyses}

Bulk-tank milk ELISA and PCR results were compiled to calculate the percentage of positive herds in the study region. In addition, ELISA results from individual serum were used to estimate overall and within-herd seroprevalence and age-specific seroprevalence. For the interpretation of results, a PCR-positive result in BTM indicated the presence of $C$. burnetii milk shedders among milking cows. A positive ELISA result in BTM or animal serum indicated previous contact with the bacterium. When antibodies against C. burnetii were detected in $\mathrm{S}_{2}$ in a BTM sample or an individual serum, but were seronegative in $\mathrm{S}_{1}$, this was considered as seroconversion in the time interval between both studies, suggesting an ongoing infection. Thus, results obtained in $\mathrm{S}_{2}$ were compared with those obtained in $\mathrm{S}_{1}$ to assess the overall (at the study region level) and the individual (at the herd level) evolution of C. burnetii epidemiological status in dairy cattle herds. Herds were classified into one of each of the 3 categories established attending to ELISA and PCR results in BTM and to individual serum ELISA results. Herd epidemiological status was classified independently in $\mathrm{S}_{1}$ and $\mathrm{S}_{2}$, with specific results obtained from herds in each study. Category A included all herds whose BTM sample was positive by ELISA and PCR and at least 1 animal was seropositive. Category B included those herds with positive BTM either by ELISA or PCR, or that at least had a seropositive animal. Finally, Cat- egory C grouped all herds with negative BTM ELISA and PCR results, and every animal included was seronegative. The change in the epidemiological status of a particular herd between studies was classified in 9 categories: (1) herds of category $\mathrm{A}$ in $\mathrm{S}_{1}$ that continued in category $\mathrm{A}$ in $\mathrm{S}_{2} ;(2)$ herds of category $\mathrm{A}$ in $\mathrm{S}_{1}$ that changed to category $\mathrm{B}$ in $\mathrm{S}_{2} ;(3)$ herds of category $\mathrm{A}$ in $\mathrm{S}_{1}$ that changed to category $\mathrm{C}$ in $\mathrm{S}_{2}$; (4) herds of category $\mathrm{B}$ in $\mathrm{S}_{1}$ that changed to category $\mathrm{A}$ in $\mathrm{S}_{2}$; (5) herds of category $\mathrm{B}$ in $\mathrm{S}_{1}$ that remained in category $B$ in $S_{2} ;(6)$ herds of category B in $S_{1}$ that changed to category $\mathrm{C}$ in $\mathrm{S}_{2} ;(7)$ herds of category $\mathrm{C}$ in $\mathrm{S}_{1}$ that changed to category $\mathrm{A}$ in $\mathrm{S}_{2} ;(8)$ herds of category $\mathrm{C}$ in $\mathrm{S}_{1}$ that changed to category $\mathrm{B}$ in $\mathrm{S}_{2}$; and (9) herds of category $\mathrm{C}$ in $\mathrm{S}_{1}$ that continued in category $\mathrm{C}$ in $\mathrm{S}_{2}$. This classification was intended to show the epidemiological changes in this cohort of dairy cattle herds in a 2 -yr period and to help classifying the real status of $C$. burnetii infection.

Chi-squared and Mann-Whitney U tests were employed to assess for any statistical significance in changes of frequencies and means, respectively. Changes in the epidemiological status of herds between studies (9 categories) were entered as response variable to a multinomial logistic regression model to assess for the effect of herd parameters (changes in herd size, presence or absence of other ruminant species - sheep or goat - in the flock in $\mathrm{S}_{1}$, and changes in the percentage of cows and heifers in the herd between $S_{1}$ and $\mathrm{S}_{2}$ ) and domestic ruminant density in the municipality where the herd was located on those changes. Domestic ruminant (cattle, sheep, and goat) density in 2009 at a municipality level was obtained from the Spanish National Statistics Institute (http://www.ine.es). Every combination of pure variables (without interactions) was modeled to obtain the final model based on Akaike Information Criterion (Akaike, 1974).

A second model was built to assess the relationship between the change in the epidemiological status of the herd, the age of animals, and $\mathrm{S} / \mathrm{P} \times 100$ results obtained from the individual serum ELISA performed on animals surveyed in both studies. A generalized linear mixed model with normal probability distribution and identity link function was built. The effect of change was corrected according to the herd of origin of animals by including herd as a random variable in the model. Statistical analyses were carried out using the IBM SPSS v19.0 software (IBM, Armonk, NY). Statistical uncertainty of the calculated prevalences was assessed by calculating the $95 \%$ CI for each of the proportions according to the expression $\mathrm{CI}_{95 \%}=1.96[p(1-p) / n]^{1 / 2}$, where $p$ is the proportion in units and $n$ is the sample size. 


\section{Hypothesizing C. burnetii Infection} Dynamics Cycle in Endemic Herds

According to the observed changes in the epidemiological status of herds, the change in seroprevalence, and BTM ELISA and PCR results, the hypothetical evolution of the dynamics of $C$. burnetii infection in endemic dairy cattle herds was drawn. This was intended to show a general pattern of temporal evolution of the epidemiological cycle of $C$. burnetii infection in dairy cattle herds without considering particular herd and management traits that could slightly modify this pattern. The cycle displays the expected evolution of seroprevalence with time as a measure of the level of herd protection against $C$. burnetii infection and shedding (taking into account that cellular immunity in the herd, although not determined, should evolve in parallel with humoral immunity), the percentage of nonimmune animals in the herd (as a measure of the expected herd susceptibility to infection), and the expected evolution of infection pressure as a measure of the expected percentage of shedding animals in the herd and environmental contamination. The proposed evolution of the withinherd dynamics of $C$. burnetii after introduction of the pathogen into a wholly susceptible herd is based on the fact that the pathogen disseminates quickly among susceptible animals. After that, infected animals start shedding $C$. burnetii in vaginal mucus and feces that contaminate herd premises (milk shedding is not considered a major route for environmental contamination; see Courcoul et al., 2011). Thereafter, the percentage of animals seroconverting in the herd starts increasing, thus decreasing the percentage of $C$. burnetii-shedding animals and environmental circulation of $C$. burnetii. This decrease in environmental circulation of $C$. burnetii determines a decrease in infection pressure. Therefore, after a threshold seroprevalence value (perhaps depending on herd and management traits) is reached, the percentage of susceptible animals starts increasing in the herd (mainly through newborn, susceptible animals kept as replacement) in contrast to the decreasing percentage of seropositive animals that are sequentially culled due to age. As C. burnetii is highly resistant, it may persist for a long time in herd premises and it may reappear once the level of susceptible animals in the herd reaches a threshold, starting a new cycle.

Maximum seroprevalence values in the cycle were set on the basis of existing literature in the study region where herd seroprevalence usually does not exceed $50 \%$ (Astobiza et al., 2012). The curve for seroconversion evolution within the herd after $C$. burnetii enters the herd or reactivates was drawn according to the modeled evolution of seroprevalence observed by Courcoul et al. (2010). The curve depicting the percentage of susceptible animals in the herd is based on the evolution of the expected percentage of immune animals and in herd reposition with newborn animals. Finally, infection pressure evolution was drawn from literature results on shedding patterns of naturally infected dairy cattle (Guatteo et al., 2006, 2007b, 2012) and from observed changes in the status of exposure to C. burnetii in young animals $(<2 \mathrm{yr})$ under changes in the epidemiological status of their herds of origin in this study. The peak and shape of the curve depicting the evolution of infection pressure was adjusted to the fifth year according to results from (Courcoul et al., 2011), which also agreed perfectly with the proposed evolution of seroprevalence. The expected decrease in infection pressure after reaching its maximum value was drawn according to the expected decrease in the percentage of susceptible animals within the herd, reaching its minimum at the time the percentage of susceptible animals is also at its minimum.

The graph was built according to the time-span of the study (2 yr) and to the expected average productive life of dairy cows (5 yr; Alonso-Hearn et al., 2012). Endemic herds in this study, those in category $\mathrm{A}$ in $\mathrm{S}_{1}$ that were in category $\mathrm{A}, \mathrm{B}$, or $\mathrm{C}$ in $\mathrm{S}_{2}$, those in category $\mathrm{B}$ in $\mathrm{S}_{1}$ that were in category $\mathrm{A}$ or $\mathrm{B}$ in $\mathrm{S}_{2}$, and those in category $\mathrm{C}$ in $\mathrm{S}_{1}$ that changed to category $\mathrm{A}$ or $\mathrm{B}$ in $\mathrm{S}_{2}$, were allocated to the seroprevalence curve of the graph according to the change experienced in seroprevalence in the 2-yr study period. Herds in category B or C in $\mathrm{S}_{1}$ that were classified in category $\mathrm{C}$ in $\mathrm{S}_{2}$ were considered as nonendemic herds.

\section{RESULTS}

\section{Changes in C. burnetii Status in the Studied Population in a 2-yr Period}

A statistically significant decrease in the overall BTM antibody prevalence was observed in $\mathrm{S}_{2}$ with respect to $\mathrm{S}_{1}\left(\chi^{2}=26.1, \mathrm{df}=1, P<0.01 ;\right.$ Table 1$)$. Similarly, a statistically significant decrease was also observed in the detection of $C$. burnetii DNA in BTM, which was found in 40 of 94 of the herds in $\mathrm{S}_{2}$ in contrast to 56 of the 94 herds in $\mathrm{S}_{1}\left(\chi^{2}=36.3\right.$, df $=1, P<0.01$; Table $1)$.

In spite of the decrease in the exposure to $C$. burnetii at the population level, a marginal statistically significant (Z-score $=-1.9$, where the Z-score indicates how a single data point compares with normal data; $P=0.053)$ increase in the individual seroprevalence was observed; presence of antibodies against $C$. burnetii increased from $6.9 \%$ in $\mathrm{S}_{1}\left(94 / 1,357 ; \mathrm{CI}_{95 \%}: 5.6-8.2\right)$ to $8.9 \%$ in $\mathrm{S}_{2}\left(122 / 1,366 ; \mathrm{CI}_{95 \%}: 7.4-10.4\right)$. Nevertheless, the composition of age groups was different in $\mathrm{S}_{2}$ with 
Table 1. Changes in Coxiella burnetii status in the studied population in a 2-yr period

Study $1(2009 / 10)$

\begin{tabular}{|c|c|c|c|c|c|c|c|c|c|c|c|}
\hline Cat. ${ }^{1}$ & $\mathrm{n}$ & $\begin{array}{c}\text { Average } \\
\text { seroprevalence }^{2} \\
\text { (SE) }\end{array}$ & $\begin{array}{c}\text { BTM }^{3} \\
\text { seroprevalence } \\
(95 \% \mathrm{CI})\end{array}$ & $\begin{array}{c}\text { BTM DNA } \\
\text { prevalence }(95 \% \\
\text { CI) }\end{array}$ & Cat. ${ }^{1}$ & $\mathrm{n}$ & $\begin{array}{l}\text { Average } \\
\text { seroprevalence } \\
\quad(\mathrm{SE})\end{array}$ & $\begin{array}{c}\text { BTM } \\
\text { seroprevalence } \\
(95 \% \text { CI })\end{array}$ & $\begin{array}{c}\text { BTM DNA } \\
\text { prevalence }(95 \% \\
\text { CI) }\end{array}$ & $\begin{array}{l}\text { Herds with } \\
\text { seroconversion }\end{array}$ & $\begin{array}{l}\text { Herds with } \\
\text { positive } \\
\text { environmental } \\
\text { samples }\end{array}$ \\
\hline \multirow[t]{3}{*}{$\mathrm{A}$} & \multirow[t]{3}{*}{46} & \multirow[t]{3}{*}{$\begin{array}{l}13.0 \\
(1.2)\end{array}$} & \multirow[t]{3}{*}{$\begin{array}{l}100.0 \\
(100.0-100.0)\end{array}$} & \multirow[t]{3}{*}{$\begin{array}{l}100.0 \\
(100.0-100.0)\end{array}$} & $\mathrm{A}$ & 29 & $\begin{array}{c}19.2 \\
(11.9)\end{array}$ & $\begin{array}{l}100.0 \\
(100.0-100.0)\end{array}$ & $\begin{array}{l}100.0 \\
(100.0-100.0)\end{array}$ & 14 & 9 \\
\hline & & & & & B & 10 & $\begin{array}{c}6.7 \\
(7.3)\end{array}$ & $\begin{array}{l}70.0 \\
(41.6-98.4)\end{array}$ & $\begin{array}{l}40.0 \\
(9.6-70.4)\end{array}$ & 3 & 0 \\
\hline & & & & & $\mathrm{C}$ & 7 & $\begin{array}{c}0.0 \\
(0.0)\end{array}$ & $\begin{array}{l}0.0 \\
(0.0-0.0)\end{array}$ & $\begin{array}{l}0.0 \\
(0.0-0.0)\end{array}$ & - & 1 \\
\hline \multirow[t]{3}{*}{ B } & \multirow[t]{3}{*}{17} & \multirow[t]{3}{*}{$\begin{array}{c}2.4 \\
(1.6)\end{array}$} & \multirow[t]{3}{*}{$\begin{array}{l}64.7 \\
(42.0-87.4)\end{array}$} & \multirow[t]{3}{*}{$\begin{array}{l}58.8 \\
(35.4-82.2)\end{array}$} & A & 4 & $\begin{array}{l}16.7 \\
(12.8)\end{array}$ & $\begin{array}{l}100.0 \\
(100.0-100.0)\end{array}$ & $\begin{array}{l}100.0 \\
(100.0-100.0)\end{array}$ & 4 & 2 \\
\hline & & & & & B & 7 & $\begin{array}{c}6.7 \\
(3.9)\end{array}$ & $\begin{array}{l}42.9 \\
(6.2-79.6)\end{array}$ & $\begin{array}{l}14.3 \\
(-11.6-40.2)\end{array}$ & 3 & 0 \\
\hline & & & & & $\mathrm{C}$ & 6 & $\begin{array}{c}0.0 \\
(0.0)\end{array}$ & $\begin{array}{l}0.0 \\
(0.0-0.0)\end{array}$ & $\begin{array}{l}0.0 \\
(0.0-0.0)\end{array}$ & - & 1 \\
\hline \multirow[t]{3}{*}{$\mathrm{C}$} & \multirow[t]{3}{*}{31} & \multirow[t]{3}{*}{$\begin{array}{c}0.0 \\
(0.0)\end{array}$} & \multirow[t]{3}{*}{$\begin{array}{l}0.0 \\
(0.0-0.0)\end{array}$} & \multirow[t]{3}{*}{$\begin{array}{l}0.0 \\
(0.0-0.0)\end{array}$} & $\mathrm{A}$ & 1 & $\begin{array}{c}6.7 \\
(0.0)\end{array}$ & $\begin{array}{l}100.0 \\
(100.0-100.0)\end{array}$ & $\begin{array}{l}100.0 \\
(100.0-100.0)\end{array}$ & 1 & 0 \\
\hline & & & & & B & 8 & $\begin{array}{c}9.2 \\
(5.0)\end{array}$ & $\begin{array}{l}25.0 \\
(-5.0-55.0)\end{array}$ & $\begin{array}{l}12.5 \\
(-10.4-35.4)\end{array}$ & 7 & 0 \\
\hline & & & & & $\mathrm{C}$ & 22 & $\begin{array}{c}0.0 \\
(0.0)\end{array}$ & $\begin{array}{l}0.0 \\
(0.0-0.0)\end{array}$ & $\begin{array}{l}0.0 \\
(0.0-0.0)\end{array}$ & - & 0 \\
\hline Total & 94 & $\begin{array}{c}6.8 \\
(0.9)\end{array}$ & $\begin{array}{l}60.6 \\
(50.7-70.5)\end{array}$ & $\begin{array}{l}59.6 \\
(49.7-69.5)\end{array}$ & & 94 & $\begin{array}{c}8.7 \\
(1.1)\end{array}$ & $\begin{array}{l}48.9 \\
(38.8-59.0)\end{array}$ & $\begin{array}{l}42.6 \\
(32.6-52.6)\end{array}$ & 32 & 13 \\
\hline
\end{tabular}

${ }^{1}$ Category (Cat.) A: BTM ELISA and PCR positive and at least 1 animal seropositive; category B: BTM ELISA or PCR positive or at least 1 animal seropositive; category C: BTM ELISA and PCR negative and all animals seronegative.

${ }^{2}$ Average herd seroprevalence calculated from individual ELISA results for each study (and associated SE for the mean).

${ }^{3} \mathrm{BTM}=$ bulk-tank milk 


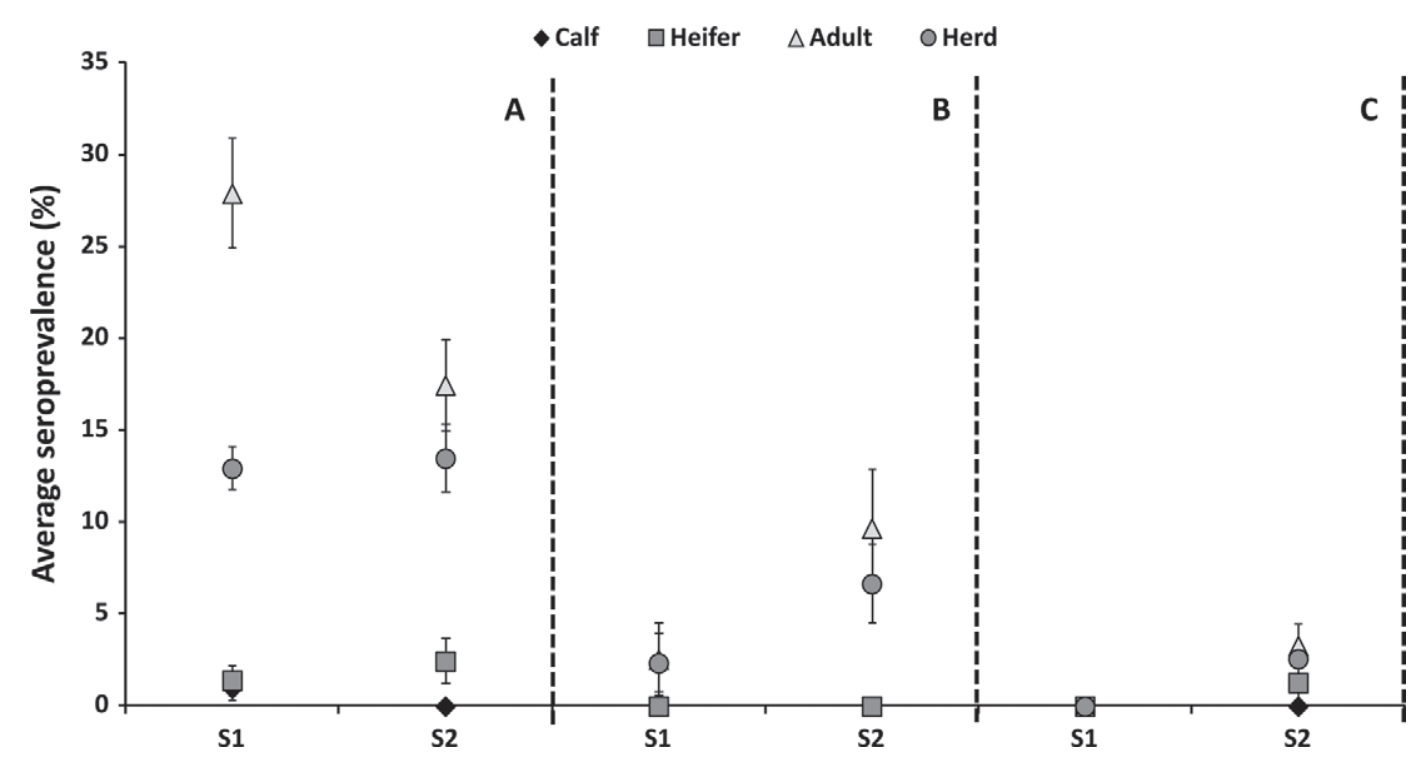

Figure 1. Average herd and age-specific seroprevalence for each study according to the epidemiological status of herds in study 1 ( $\mathrm{S}_{1}$; categories A, B, or C according to text and Table 1).

respect to $\mathrm{S}_{1}$. Whereas 308 calves were sampled in $\mathrm{S}_{1}$, in $\mathrm{S}_{2}$ the strategy was to collect as many samples as possible from the animals previously surveyed in $\mathrm{S}_{1}$ to study seroconvertion rates. Thus, the number of calves sampled and analyzed in $\mathrm{S}_{2}$ was low $(\mathrm{n}=19)$. According to this, for the comparison of evolution of individual seroprevalence between studies of only animals $>1$ yr old were taken into account, finding similar seroprevalences $\left[8.9 \%(93 / 1,049)\right.$ in $\mathrm{S}_{1}$ vs. $9.1 \%(122 / 1,347)$ in $\mathrm{S}_{2}$ ]. The percentage of herds with at least 1 seropositive animal increased from $52.1 \%$ in $\mathrm{S}_{1}\left(\mathrm{CI}_{95 \%}: 42.0-62.2\right)$ to $56.4 \%$ in $\mathrm{S}_{2}\left(\mathrm{CI}_{95 \%}\right.$ : 46.4-66.4).

Changes of $C$. burnetii epidemiological status in the studied herds in $\mathrm{S}_{2}$ according to the categories established in $\mathrm{S}_{1}$ are summarized in Table 1. The total number of herds in category A decreased in $\mathrm{S}_{2}$, but 5 herds formerly in category $\mathrm{B}$ or $\mathrm{C}$ became category $\mathrm{A}$ in $\mathrm{S}_{2}$. On the contrary, negative herds classified initially in category $\mathrm{C}$ decreased from 31 to 22 , but 13 additional herds belonging to category $\mathrm{A}$ and $\mathrm{B}$ in $\mathrm{S}_{1}$ became $C$. burnetii-negative (category $\mathrm{C}$ ) in $\mathrm{S}_{2}$. Overall, a total of 34,25 , and 35 herds were included in categories A, $\mathrm{B}$, and $\mathrm{C}$ in $\mathrm{S}_{2}$, respectively, compared with 46,17 , and 31 in $\mathrm{S}_{1}$, respectively. No change was observed in the average herd seroprevalence in category A herds in $\mathrm{S}_{1}(13.0 \pm 1.2 \%)$ compared with $\mathrm{S}_{2}(13.5 \pm 1.8 \%)$, although seroprevalence decreased with regard to animal age in adult cows and slightly increased in heifers and decreased in calves (Figure 1A). In those herds classified in category $\mathrm{B}$ in $\mathrm{S}_{1}$, changes consisted of an increase in average herd seroprevalence $(2.4 \pm 1.6 \%$ and $6.2 \pm 2.2 \%$ in $\mathrm{S}_{1}$ and $\mathrm{S}_{2}$, respectively); although se- roprevalence increased only in adult cows (Figure 1B). Finally, in herds in category $\mathrm{C}$ in $\mathrm{S}_{1}$, a slightly statistically significant (Z-score $=-3.0, P<0.01$ ) increase in seroprevalence $\left(0.0 \pm 0.0 \%\right.$ and $2.6 \pm 0.9 \%$ in $S_{1}$ and $\mathrm{S}_{2}$, respectively) was observed, which was seen in adults and heifers only (Figure 1C).

No significant differences in average herd seroprevalence were observed in herds in category A that remained in that category or changed to category $\mathrm{B}$ (Figure 2). Conversely, seroprevalence in $\mathrm{S}_{2}$ differed statistically from $\mathrm{S}_{1}$ in herds that changed from category A to $\mathrm{C}(0.0 \pm 0.0 \%$ and $9.1 \pm 1.6 \%$, respectively; Z-score $=-3.4, P<0.05$; Figure 2). For herds in category $\mathrm{B}$ in $\mathrm{S}_{1}$, average herd seroprevalence only changed significantly in those herds that changed to category A (Z-score $=-2.5, P<0.05$; Figure 2). Changes in the epidemiological status of herds, considering category $\mathrm{C}$ herds that remained in category $\mathrm{C}$ as a reference, were only influenced by the density of domestic ruminants in the municipality (Table 2).

A total of 656 of 1,393 animals sampled in $\mathrm{S}_{2}$ had been previously analyzed in $\mathrm{S}_{1}$; seroconversion was observed in 53 of 656 animals $\left(8.1 \% ; \mathrm{CI}_{95 \%}: 6.0-10.2\right)$. A low number of animals became seronegative $(6 / 656$, $\left.0.9 \% ; \mathrm{CI}_{95 \%}: 0.2-1.6\right)$. Herds with seroconversion (n $=33$ ) were mainly included in category $\mathrm{A}$ and $\mathrm{B}$ in $\mathrm{S}_{2}(\mathrm{n}=19$ and $\mathrm{n}=14$, respectively; Table 1$)$, with seroprevalence ranging between 6.7 and $53.3 \%$ and 6.7 and $13.3 \%$, respectively. Every age class from $\mathrm{S}_{1}$ experienced a significant increase in seroprevalence in $\mathrm{S}_{2}$ (Figure 3a), especially when belonging to herds in category $\mathrm{A}$ and $\mathrm{B}$ in $\mathrm{S}_{1}$ (Figure $3 \mathrm{~b}$ ). The increase in 


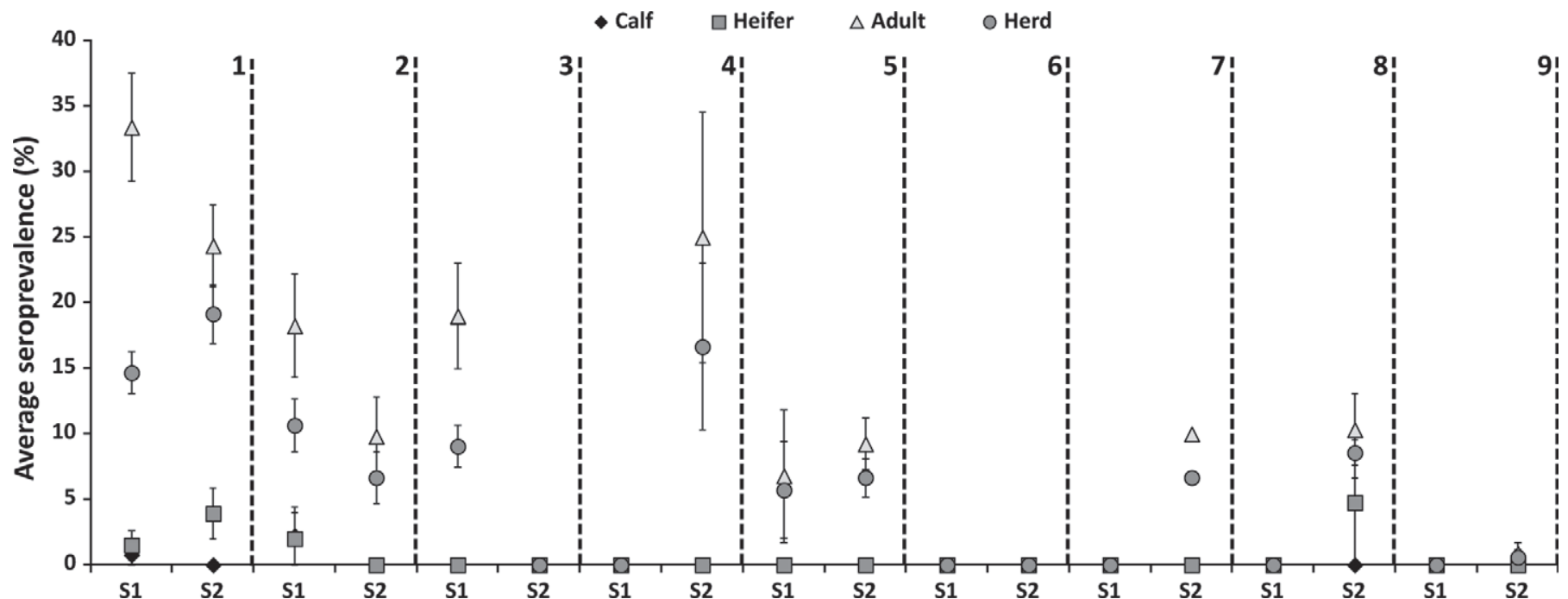

Figure 2. Average herd and age-specific seroprevalence in study 1 and $2\left(\mathrm{~S}_{1}\right.$ and $\left.\mathrm{S}_{2}\right)$ according to changes in the epidemiological status of herds between studies. (1) Herds of category A in $\mathrm{S}_{1}$ that continued in category A in $\mathrm{S}_{2}$. (2) Herds of category A in $\mathrm{S}_{1}$ that changed to category B in $S_{2}$. (3) Herds of category A in $S_{1}$ that changed to category C in $S_{2}$. (4) Herds of category B in $S_{1}$ that changed to category A in $S_{2}$. (5) Herds of category B in $\mathrm{S}_{1}$ that remained in category B in $\mathrm{S}_{2}$. (6) Herds of category B in $\mathrm{S}_{1}$ that changed to category C in $\mathrm{S}_{2}$. (7) Herds of category C in $\mathrm{S}_{1}$ that changed to category A in $\mathrm{S}_{2}$. (8) Herds of category C in $\mathrm{S}_{1}$ that changed to category B in $\mathrm{S}_{2}$. (9) Herds of category C in $\mathrm{S}_{1}$ that continued in category $\mathrm{C}$ in $\mathrm{S}_{2}$. Herd epidemiological status categories (A, B, and C) are defined in the text and Table 1.

prevalence in these animals was higher in category A herds that remained in category A, category B herds that changed to category $\mathrm{A}$ or remained in category $\mathrm{B}$, and in category $\mathrm{C}$ herds that changed to category A or B. A slight increase was observed in category A herds that changed to category B (Figure 4). No sero- conversion was observed in seronegative animals from category A herds that changed to category C, category $\mathrm{B}$ herds that become category $\mathrm{C}$, and category $\mathrm{C}$ herds that remained negative. The best fitted model for the individual change in C. burnetii antibody levels between $\mathrm{S}_{1}$ and $\mathrm{S}_{2}$ showed that it was significantly influenced

Table 2. Final model outputs [coefficient $(\beta)$, SE, statistic $(F), 95 \%$ CI, df, and significance value] obtained for changes in the epidemiological status of herds (9 categories as shown in Figure 2) between study 1 and $2\left(\mathrm{~S}_{1}\right.$ and $\mathrm{S}_{2}$ ) and for changes in antibody levels (sample-to-positive control ratio $\times 100$ values) in individuals surveyed both in $\mathrm{S}_{1}$ and $\mathrm{S}_{2}$

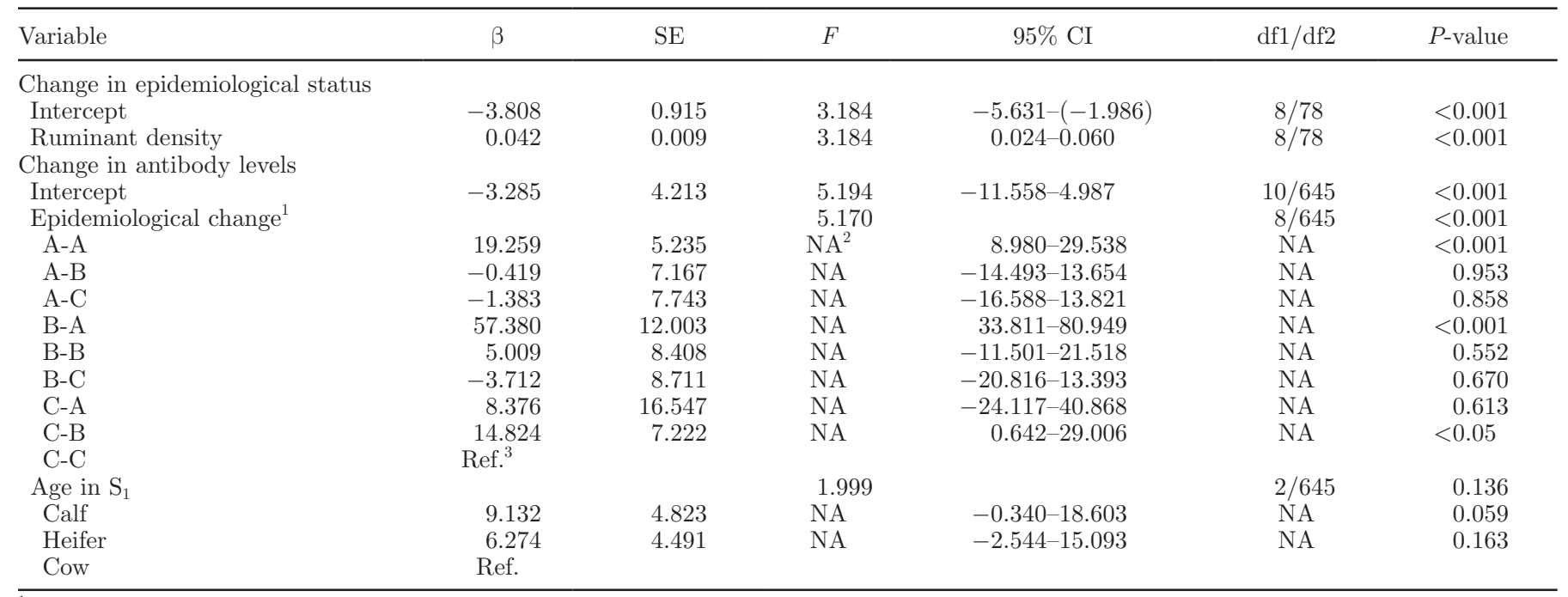

${ }^{1}$ Category A: BTM ELISA and PCR positive and at least 1 animal seropositive; category B: BTM ELISA or PCR positive or at least 1 animal seropositive; category C: BTM ELISA and PCR negative and all animals seronegative.

${ }^{2} \mathrm{NA}=$ not applicable.

${ }^{3}$ Ref. $=$ referent. 
by changes in the epidemiological status of the herd, but not by the age of animals (Table 2). Changes in individual antibody levels between studies were statistically significant only in herds in category $\mathrm{A}$ in $\mathrm{S}_{1}$ that remained in category $\mathrm{A}$ in $\mathrm{S}_{2}$, in category B herds that became category $\mathrm{A}$ in $\mathrm{S}_{2}$, and in category $\mathrm{C}$ herds that became category $\mathrm{B}$ in $\mathrm{S}_{2}$ (Table 2). Herd size statistically differed between category $\mathrm{A}, \mathrm{B}$, and $\mathrm{C}$ herds in both studies, being higher in category A $(87.5 \pm 62.3$ and $112.1 \pm 85.3$ in $\mathrm{S}_{1}$ and $\mathrm{S}_{2}$, respectively) than in category B $\left(64.4 \pm 41.0\right.$ and $59.9 \pm 29.5$ in $\mathrm{S}_{1}$ and $\mathrm{S}_{2}$, respectively) and category $\mathrm{C}(43.9 \pm 26.0$ and $45.5 \pm$ 44.4 in $\mathrm{S}_{1}$ and $\mathrm{S}_{2}$, respectively).

\section{Herd Allocation to the Hypothetical Epidemiological Cycle of C. burnetii}

Herds in category $\mathrm{A}$ in $\mathrm{S}_{1}$ were set to the time of the hypothesized epidemiological cycle of $C$. burnetii in which herd seroprevalence reaches its maximum in the herd (Figure 5), the percentage of susceptible animals is at its lowest value, and infection pressure is decreasing. Those herds in category $\mathrm{A}$ in $\mathrm{S}_{1}$ that remained in category $\mathrm{A}$ in $\mathrm{S}_{2}$ reached its highest seroprevalence in $\mathrm{S}_{2}$, when seroprevalence in calves, heifers, or adults from $\mathrm{S}_{1}$ increased, further indicating that $C$. burnetii was still active in the herd at that moment. In contrast, category A herds in $\mathrm{S}_{1}$ changing to category $\mathrm{B}$ and $\mathrm{C}$ in $\mathrm{S}_{2}$ tended to decrease herd seroprevalence, which was also reflected by practically no change in seroprevalence in animals of any age from $S_{1}$ that were surveyed again in $S_{2}$. Herds of category B in $S_{1}$ that became category A or remained in category $B$ in $S_{2}$ were set on the graph when a reactivation of the circulation of $C$. burnetii in the herd was expected to happen as changes 2 yr later suggested. In these herds, seroprevalence increased in $\mathrm{S}_{2}$ with respect $\mathrm{S}_{1}$ (and this was also noted when observing the seroconversion rate of animals in these herds). Finally, herds in category $\mathrm{C}$ in $\mathrm{S}_{1}$ that became category $\mathrm{A}$ or cat $\mathrm{B}$ in $\mathrm{S}_{2}$ were set to the epidemiological cycle of $C$. burnetii infection at the time in which infection pressure was increasing and seroprevalence tended to increase, which was evidenced both in herd seroprevalence changes and in seroconversion rates.

\section{C. burnetii in the Environment in the Different Herds Categories}

A total of 17 out of 470 dust samples (3.6\%; C.I.95\%: 1.9-5.3) collected from surfaces were positive to the presence of $C$. burnetii DNA. These positive samples were concentrated in $12.8 \%$ of the herds (12/94). Slurry samples from 4 herds were also positive $(4.2 \%, 4 / 94)$. In 3 of these 4 herds, C. burnetii DNA was also de- tected in dust from surfaces. These 4 positive herds were classified in category $\mathrm{A}$ in $\mathrm{S}_{1}$ and remained in category $\mathrm{A}$ in $\mathrm{S}_{2}$ (Table 3). Dust and slurry samples results suggested that $C$. burnetii was recently circulating in the environment in $13.8 \%(13 / 94)$ of the studied herds. Seroconversion was observed in 8 of these herds, whereas the seroprevalence decreased in 2 of them; in the remaining 3 , no changes in individual seroprevalence were observed (Table 3). Herds in category A in $\mathrm{S}_{2}$ had a significantly higher percentage of dust samples positive to $C$. burnetii DNA $(8.8 \%$ in category A vs. $1.1 \%$ in category $\mathrm{C} ; \chi^{2}=13.83$, df $=2, P<0.05$; Table 1). However, no positive dust sample was found in herds of category $\mathrm{C}$ in $\mathrm{S}_{1}$, independently of the epidemiological change experienced. The highest percentages of positive dust samples were obtained from category A herds that remained category A and from category B herds that became category A, suggesting that the levels of $C$. burnetii circulating in the environment were higher in herds with an active infection detected through presence of antibodies in BTM or individuals and detection of C. burnetii DNA in BTM (Table 3). A significant correlation between the percentage of dust samples positive to $C$. burnetii and $C$. burnetii antibodies level in BTM samples ( rho $=0.36, P<0.001$ ), and within herd seroprevalence (rho $=0.30, P<0.0001$ ) was found.

\section{Relationship Between C. burnetii Status, Production, and Management}

Eleven herds reported reproductive problems in the questionnaires filled out in $\mathrm{S}_{2}$; from those, 3 herds had also reported problems in $\mathrm{S}_{1}$. Overall, within-herd seroprevalence in herds with reproductive problems in $\mathrm{S}_{2}$ was higher compared with herds that reported no problems (15.9 vs. 9.5\%), but differences were not statistically significant. Another interesting observation derived from the analysis of collected farm management data was the association between presence of other livestock species in the farm (24/92 farms) and a higher C. burnetii seroprevalence (16.4 vs. $9.0 \%, P=0.0943)$.

\section{DISCUSSION}

$\mathrm{Q}$ fever is an endemic disease in the Basque country, and sheep have been identified as the main source of C. burnetii for human infections in the region (Cilla et al., 2008; García-Pérez et al., 2009; Ruiz-Fons et al., 2010). However, dairy cattle could also play an important role within the domestic cycle of Q fever (EFSA, 2010), and cattle farms are abundant and widespread in the Basque country. Several studies have shown a high prevalence of $C$. burnetii in dairy cattle worldwide 


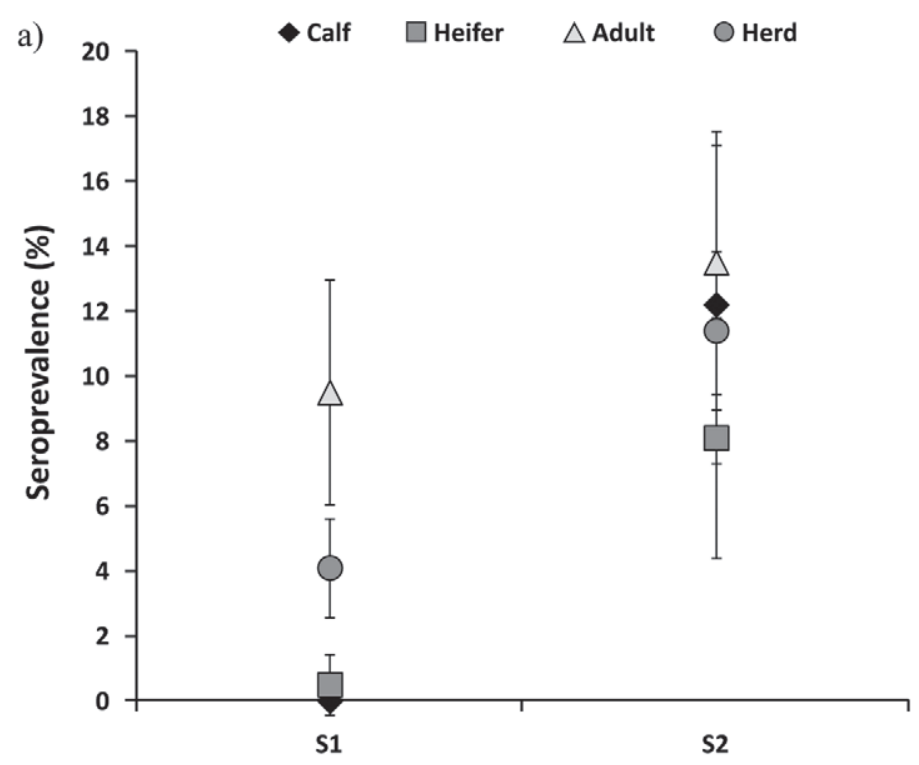

b)

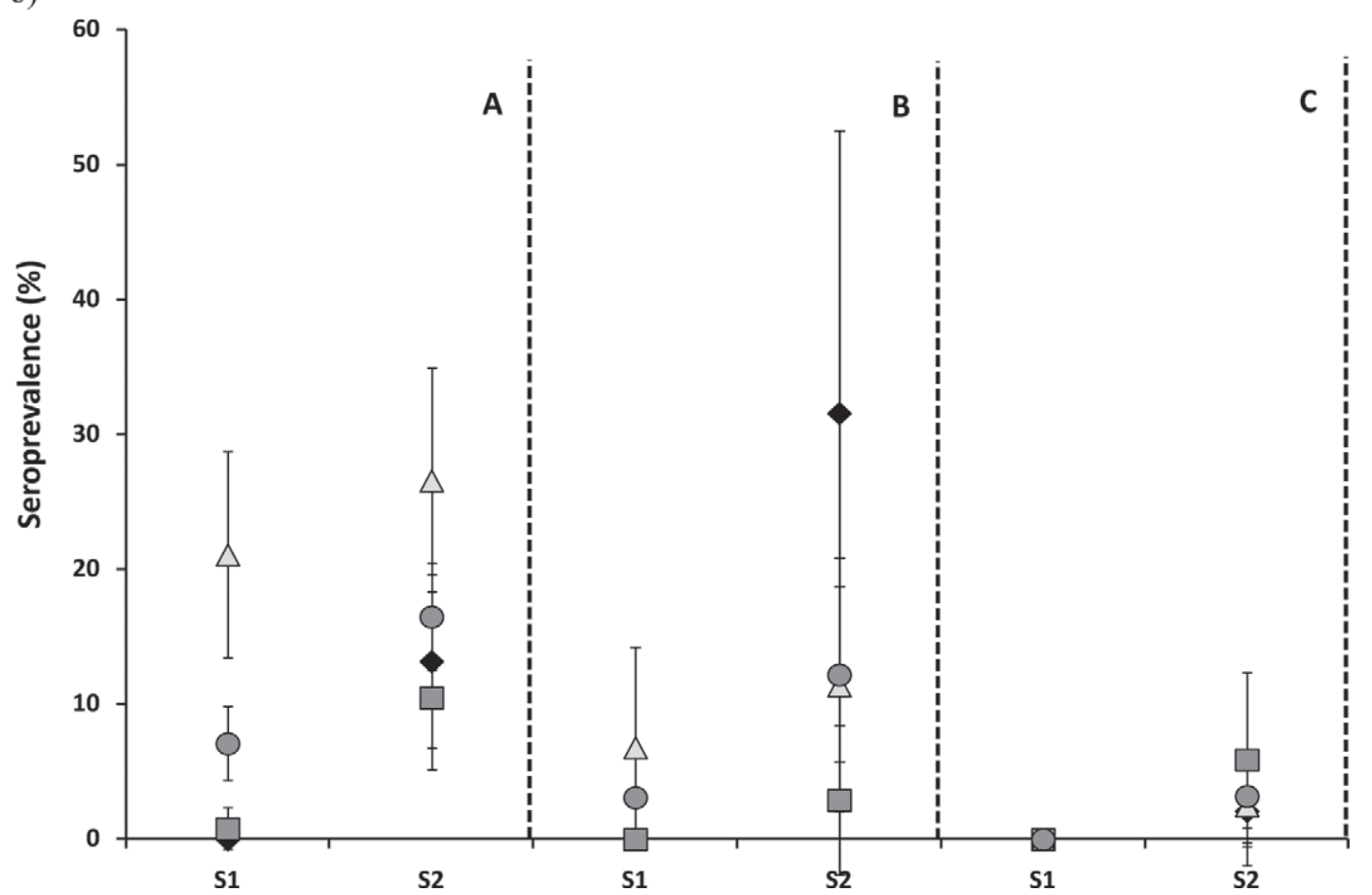

Figure 3. Individual herd and age-specific seroprevalence values in study 1 and $2\left(\mathrm{~S}_{1}\right.$ and $\mathrm{S}_{2}$; a) and values according to the epidemiological status of herds of origin in $\mathrm{S}_{1}(\mathrm{~b})$ in animals surveyed in both studies $(\mathrm{n}=656)$. Herd epidemiological status categories $(\mathrm{A}, \mathrm{B}$, and $\mathrm{C})$ are defined in the text and Table 1.

(Kim et al., 2005; Agger et al., 2010; Muskens et al., 2011a), and also in the Basque country (Astobiza et al., 2012). Predicting risks and implementing efficient control tools (e.g., vaccination) require an exhaustive follow-up of the epidemiological status of herds in endemic regions (Astobiza et al., 2011a, b). Vaccination of endemic herds would not be as efficient as expected if a high percentage of animals were seropositive (Guatteo et al., 2008); hence, vaccination is ideally recommended to seronegative herds or herds where seroprevalence is low. Any vaccination approach in endemic herds with medium- to high-seroprevalence levels would fail to prevent shedding of C. burnetii (Astobiza et al., 2011a, b). Thus, predicting the evolution of $C$. burnetii infection dynamics in the herd is crucial to determine the optimal timeframe to apply the vaccine, that is, when 


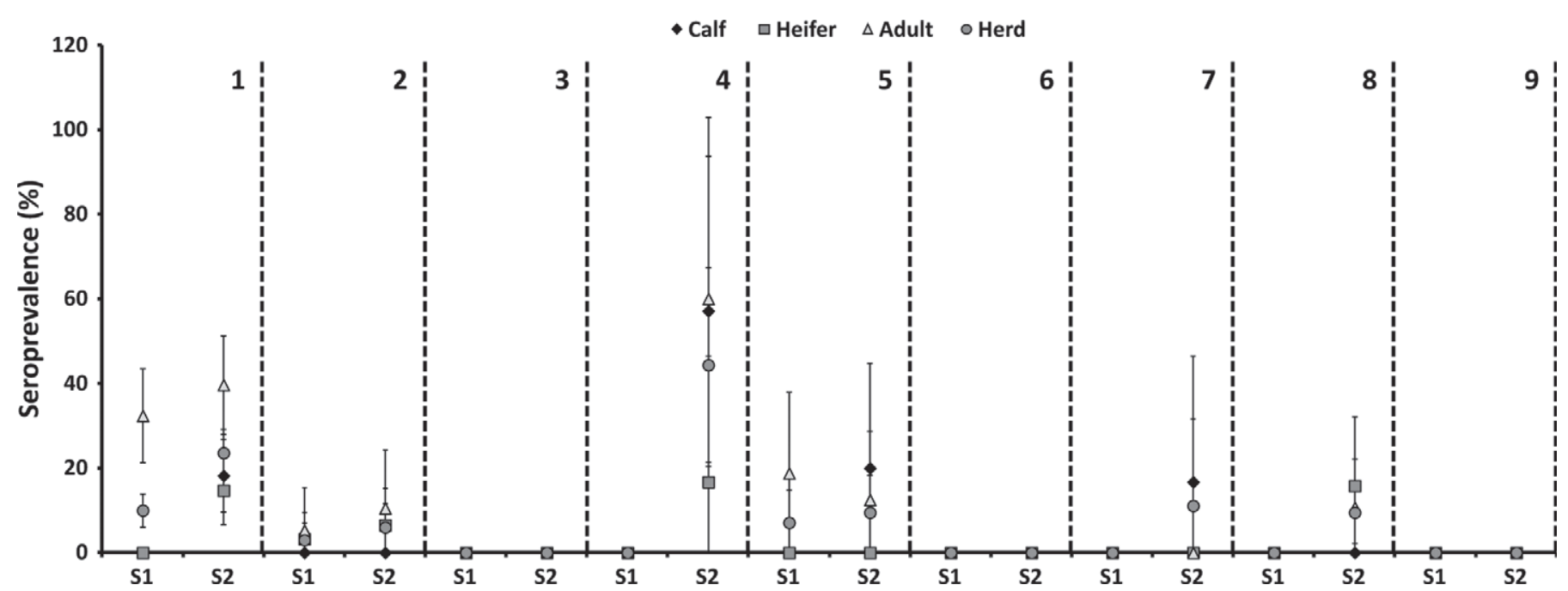

Figure 4. Individual herd and age-specific seroprevalence values in study 1 and $2\left(\mathrm{~S}_{1}\right.$ and $\left.\mathrm{S}_{2}\right)$ according to changes in the epidemiological status of herds between $\mathrm{S}_{1}$ and $\mathrm{S}_{2}$ as described in the text and Figure 2 .

the number of susceptible animals is at its maximum in the herd and the percentage of immune animals is at its minimum.
The present study showed a decreasing trend in the prevalence of $C$. burnetii in dairy cattle in the Basque country in a 2 -yr period. Nevertheless, C. burnetii prev-

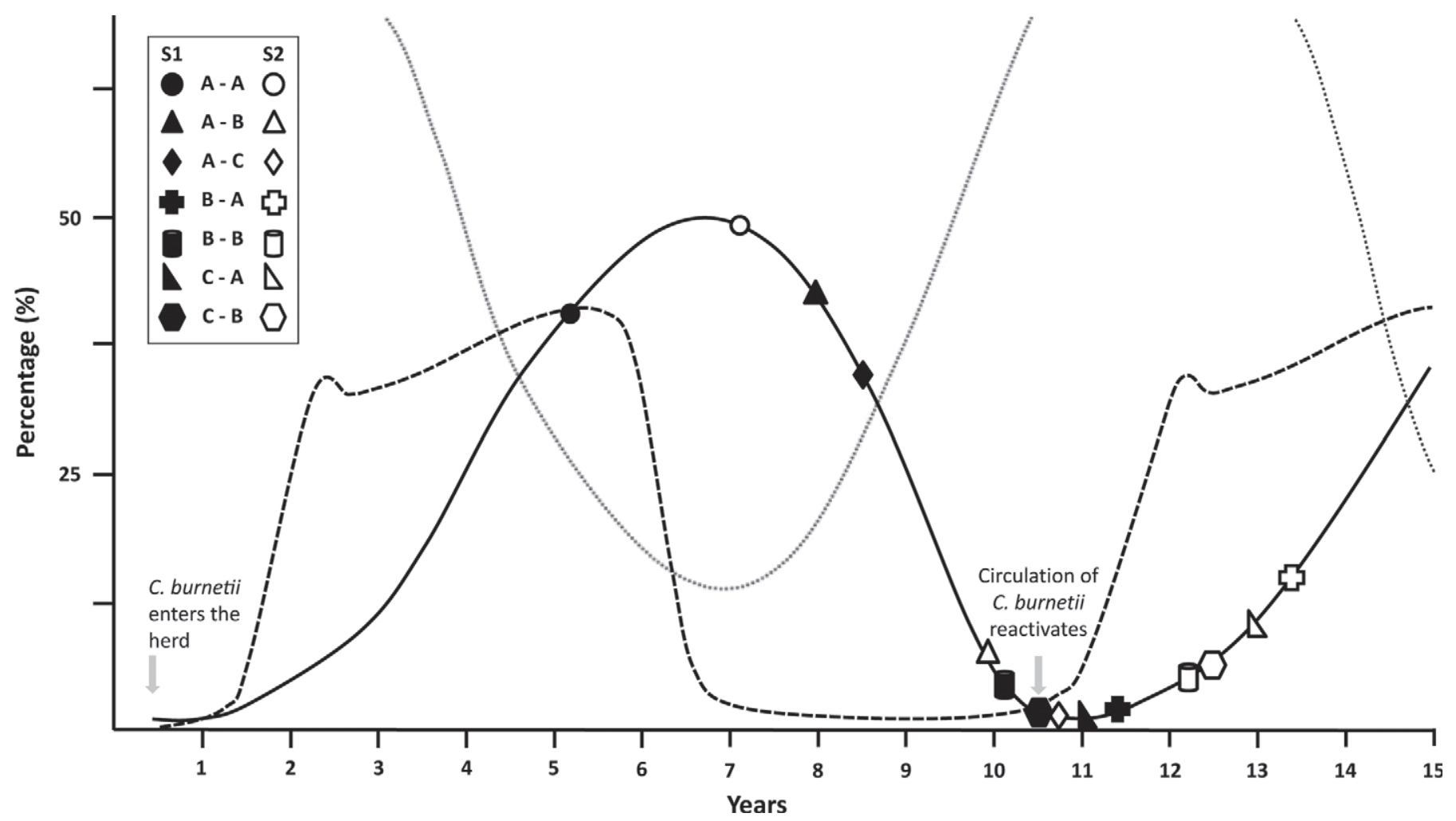

Figure 5. Draft of the expected epidemiological cycle of Coxiella burnetii in endemic dairy cattle herds according to observations of changes in the epidemiological status of herds in this study. Herd status regarding seroprevalence (continuous line), percentage of susceptible animals in the herd (dotted line), and infection pressure (dash line) are displayed in the figure (see text for details). Allocation of changes in the epidemiological status of endemic herds in the current study are adjusted to the curve in herd seroprevalence. Herd epidemiological status categories (A, $\mathrm{B}$, and $\mathrm{C}$ ) are defined in the text and Table 1. 


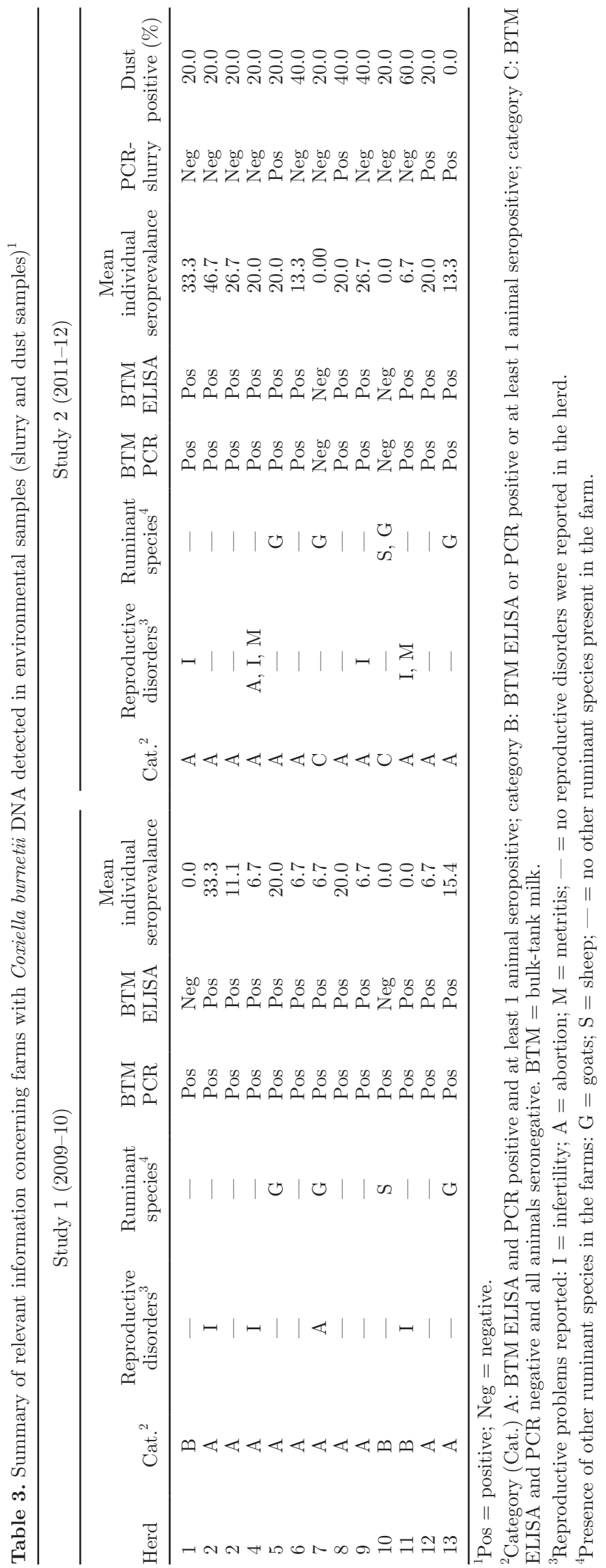

alence still remained high and similar to levels reported in other studies (McCaughey et al., 2010; Ryan et al., 2011), demonstrating the relatively high prevalence of current or past infections in the cattle population of northern Spain, which could have zoonotic implications. Forty percent of herds with PCR-positive BTM confirmed the existence of shedder cows. An important number of farms initially located in category A remained in the same category 2 yr later, indicating that $C$. burnetii infection lasts quite long and can remain within a population for a long time, more than 2 yr according to the present results. Antibodies in dairy cattle were rather stable during several months, in agreement with Angen et al. (2011). The significant number of herds with intermediate values (category B) in $\mathrm{S}_{2}$ and the seroconversion rates (6.7-13.3\%), suggest that some of these herds might be undergoing an infection, as discussed in similar studies (Böttcher et al., 2011). A few herds that initially tested negative converted to positive, suggesting the risk of acquiring C. burnetii infection from other herds or through the purchase of animals, stressing the importance of quarantine practices (EFSA, 2010). Also, veterinarians and hoof trimmers could act as carriers, introducing the pathogen from infected farms (Paul et al., 2012). Unfortunately, all these hypotheses could not be confirmed, as the questionnaire done at sampling included only limited information about the size of the herd, reproductive problems, and presence of other ruminant species, among others. Here, herd size statistically differed between herd categories in both studies, being higher in category A with respect to the others, probably due to an increased transmission probability with the increasing number of cows in a herd (Paul et al., 2012).

In spite of the decline in the number of BTM PCRor ELISA-positive herds, within-herd seroprevalence did not change in the 2-yr period. Animals younger than 1 yr showed a lower seroprevalence than heifers and cows due to the increasing contact with $C$. burnetii with age, as previously described (Böttcher et al., 2011; Ruiz-Fons et al., 2010; Paul et al., 2012). Mean seroprevalence found in calves, heifers, and cows were within ranges found in other studies carried out in dairy cattle (Böttcher et al., 2011; Paul et al., 2012). Although differences were not significant, farms that reared other species of domestic ruminants presented a higher within-herd seroprevalence than farms without sheep or goats. This result supports the role of small ruminants as reservoirs and main transmitters of $\mathrm{Q}$ fever, and observed by the associated risks for cattle in close contact with these species (Taurel et al., 2011). No significant association was found between seroprevalence against $C$. burnetii and reproductive 
problems in the farm. Interestingly, in locations with a high prevalence of $C$. burnetii in cattle herds (Muskens et al., 2011a), the implication of this pathogen in abortions (Muskens et al., 2012) and reproductive problems is rare (Muskens et al., 2011b). The high prevalence of C. burnetii, its maintenance in the herds, and the lack of association between seroprevalence and reproductive problems, suggests that $C$. burnetii could persist for long time in a herd without causing significant clinical signs.

How cattle become infected (aerosols, ingestion, intrauterine infection, and so on) is not known, but the inhalation of contaminated aerosols seems to be the main route (Angelakis and Raoult, 2010). Presence of C. burnetii DNA in the farm environment suggests that resistance to the bacteria can pose a risk for transmission to susceptible animals and humans. In case of favorable climatic conditions, $C$. burnetii-resistant forms could be transported by wind and cause infection far away from infected animal premises. This was observed recently in a massive environmental sampling carried out in 6 states from the United States, where $23.8 \%$ of environmental samples taken from places with animal presence or in urban locations were positive (Kersh et al., 2010). In relation with recent Q fever outbreaks, the presence of contaminated aerosols with $C$. burnetii or its presence in dust taken from animal premises confirmed potential transmission risks to humans (Astobiza et al., 2011a, b; de Bruin et al., 2012; Piñero et al., 2012). In the present study, a total of 21 environmental samples distributed throughout 13 of the 94 herds were positive to the presence of $C$. burnetii DNA and were mostly concentrated in herds from category A. Most of these herds had shown seroconversion and 6 herds had reported recent reproductive disorders associated to Q fever. Interestingly, in a recent study carried out in the Netherlands within the human Q fever outbreak occurred in 2007, C. burnetii was also detected in aerosols and dust from negative goat farms (de Bruin et al., 2012) located at 3 to $25 \mathrm{~km}$ from positive herds. In the current study, distance between farms with positive environmental samples was within similar ranges (data not shown). The detection of $C$. burnetii in negative farms in $\mathrm{S}_{2}$ (formerly in category $\mathrm{A}$ or B in $\mathrm{S}_{1}$ ) could be the result of the long-lasting persistence of environmental spores of $C$. burnetii in the environment in farms that suffered Q fever in recent years (Angelakis and Raoult, 2010), nondetected low levels of infection in animals (de Bruin et al., 2012), or even contamination by wind-borne transmitted dust (Tissot-Dupont et al., 1999; Kersh et al., 2010).

The allocation of the herds in both studies to the hypothetical epidemiological cycle of evolution of $C$. burnetii infection dynamics in endemic herds matched perfectly the evolution in seroprevalence in these herds over the 2-yr study period (Figure 5). It also agreed with the seroconversion rate in animals sampled in both studies (which was statistically influenced by changes in the epidemiological status of the herd to which they belonged), the presence of C. burnetii DNA in BTM, and the detection of the pathogen in environmental samples. We propose that these herds are at different times in the epidemiological cycle of $C$. burnetii and show the expected evolution according to host-pathogen interactions at the within-herd level based on the susceptible-infected-immune ratio variation in the herd (Courcoul et al., 2011). Density of ruminants in the neighborhood may affect the epidemiological cycle of C. burnetii in the herd, as these may act as a significant exogenous source of $C$. burnetii borne by wind under adequate environmental conditions (Kersh et al., 2010). Although herd size and composition (percentages of heifers and cows) had no effect on the change in herd epidemiological status, herd size was statistically higher in category A than in category B and C herds. Key parameters for the proposed cycle have never been determined. Therefore, time-trend studies on the evolution of $C$. burnetii infection in endemic dairy cattle herds are needed to corroborate the proposed hypothetical cycle and to estimate within- and between-herd factors related to variations in this cycle.

\section{ACKNOWLEDGMENTS}

This study was supported by Instituto Nacional de Tecnología Agraria y Alimentaria (INIA, Madrid, Spain) RTA 2009-00017-00 and the European Regional Development Fund (Brussels, Belgium). A. Piñero is the recipient of a predoctoral fellowship from INIA. F. Ruiz-Fons is funded by the Spanish Ministry for Economy and Competitiveness (Madrid, Spain) through a 'Juan de la Cierva' contract.

\section{REFERENCES}

Agerholm, J. S. 2013. Coxiella burnetii associated reproductive disorders in domestic animals - A critical review. Acta Vet. Scand. $55: 13$.

Agger, J. F., A. B. Christoffersen, E. Rattenborg, J. Nielsen, and J. S. Agerholm. 2010. Prevalence of Coxiella burnetii antibodies in Danish dairy herds. Acta Vet. Scand. 52:5.

Akaike, H. 1974. A new look at the statistical model identification. Automatic Control, IEEE Transactions on 19:716-723.

Alonso-Hearn, M., E. Molina, M. Geijo, P. Vazquez, I. A. Sevilla, J. M. Garrido, and R. A. Juste. 2012. Immunization of adult dairy cattle with a new heat-killed vaccine is associated with longer productive life prior to cows being sent to slaughter with suspected paratuberculosis. J. Dairy Sci. 95:618-629.

Angelakis, E., and D. Raoult. 2010. Q fever. Vet. Microbiol. 140:297309

Angen, Ø., M. Stahl, J. S. Agerholm, B. Christoffersen, and J. F. Agger. 2011. Dynamics of relationship between the presence of 
Coxiella burnetii DNA, antibodies, and intrinsic variables in cow milk and bulk tank milk from Danish dairy cattle. J. Dairy Sci. 94:5750-5759.

Astobiza, I., J. F. Barandika, F. Ruiz-Fons, A. Hurtado, I. Povedano, R. A. Juste, and A. L. Garcia-Perez. 2011a. Coxiella burnetii shedding and environmental contamination at lambing in two highly naturally-infected dairy sheep flocks after vaccination. Res. Vet. Sci. 91:e58-e63.

Astobiza, I., J. F. Barandika, F. Ruiz-Fons, A. Hurtado, I. Povedano, R. A. Juste, and A. L. Garcia-Perez. 2011b. Four-year evaluation of the effect of vaccination against Coxiella burnetii on reduction of animal infection and environmental contamination in a naturally infected dairy sheep flock. Appl. Environ. Microbiol. 77:7405-7407.

Astobiza, I., F. Ruiz-Fons, A. Pinero, J. F. Barandika, A. Hurtado, and A. L. Garcia-Perez. 2012. Estimation of Coxiella burnetii prevalence in dairy cattle in intensive systems by serological and molecular analyses of bulk-tank milk samples. J. Dairy Sci. 95:1632-1638.

Berri, M., K. Laroucau, and A. Rodolakis. 2000. The detection of Coxiella burnetii from ovine genital swabs, milk and fecal samples by the use of a single touchdown polymerase chain reaction. Vet. Microbiol. 72:285-293.

Böttcher, J., A. Vossen, B. Janowetz, M. Alex, A. Gangl, A. Randt, and N. Meier. 2011. Insights into the dynamics of endemic Coxiella burnetii infection in cattle by application of phase-specific ELISAs in an infected dairy herd. Vet. Microbiol. 151:291-300.

Cilla, G., M. Montes, and E. Pérez-Trallero. 2008. Q fever in the Netherlands-What matters is seriousness of disease rather than quantity. Euro Surveill. 13:18975.

Courcoul, A., H. Monod, M. Nielen, D. Klinkenberg, L. Hogerwerf, F. Beaudeau, and E. Vergu. 2011. Modelling the effect of heterogeneity of shedding on the within herd Coxiella burnetii spread and identification of key parameters by sensitivity analysis. J. Theor. Biol. 284:130-141.

Courcoul, A., E. Vergu, J. B. Denis, and F. Beaudeau. 2010. Spread of Q fever within dairy cattle herds: Key parameters inferred using a Bayesian approach. Proc. Biol. Sci. 277:2857-2865.

de Bruin, A., R. Q. van der Plaats, L. de Heer, R. Paauwe, B. Schimmer, P. Vellema, B. J. van Rotterdam, and Y. T. van Duynhoven. 2012. Detection of Coxiella burnetii DNA on small-ruminant farms during a Q fever outbreak in the Netherlands. Appl. Environ. Microbiol. 78:1652-1657.

EFSA. 2010. Scientific opinion on Q fever. EFSA J. 8:1595.

Evstigneeva, A. S., A. I. Komarova, N. F. Fetisova, V. A. Makarova, and I. V. Tarasevich. 2005. Survival of Coxiella burnetii in soil. Zh. Mikrobiol. Epidemiol. Immunobiol. 6:57-59.

García-Pérez, A. L., I. Astobiza, J. F. Barandika, R. Atxaerandio, A. Hurtado, and R. A. Juste. 2009. Short communication: Investigation of Coxiella burnetii occurrence in dairy sheep flocks by bulktank milk analysis and antibody level determination. J. Dairy Sci. 92:1581-1584.

Guatteo, R., F. Beaudeau, M. Berri, A. Rodolakis, A. Joly, and H. Seegers. 2006. Shedding routes of Coxiella burnetii in dairy cows: Implications for detection and control. Vet. Res. 37:827-833.

Guatteo, R., F. Beaudeau, A. Joly, and H. Seegers. 2007a. Assessing the within-herd prevalence of Coxiella burnetii milk-shedder cows using a real-time PCR applied to bulk tank milk. Zoonoses Public Health 54:191-194.

Guatteo, R., F. Beaudeau, A. Joly, and H. Seegers. 2007b. Coxiella burnetii shedding by dairy cows. Vet. Res. 38:849-860.

Guatteo, R., A. Joly, and F. Beaudeau. 2012. Shedding and serological patterns of dairy cows following abortions associated with Coxiella burnetii DNA detection. Vet. Microbiol. 155:430-433.

Guatteo, R., H. Seegers, A. Joly, and F. Beaudeau. 2008. Prevention of Coxiella burnetii shedding in infected dairy herds using a phase I C. burnetii inactivated vaccine. Vaccine 26:4320-4328.
Hunink, J. E., T. Veenstra, W. van der Hoek, and P. Droogers. 2010. Q fever transmission to humans and local environmental conditions. Report 90, FutureWater, Wageningen, the Netherlands. Accessed Dec. 10, 2010. http://www.futurewater.nl/downloads/2010_ Hunink_FW90.pdf.

Kersh, G. J., T. M. Wolfe, K. A. Fitzpatrick, A. J. Candee, L. D. Oliver, N. E. Patterson, J. S. Self, R. A. Priestley, A. D. Loftis, and R. F. Massung. 2010. Presence of Coxiella burnetii DNA in the environment of the United States, 2006 to 2008. Appl. Environ. Microbiol. 76:4469-4475.

Kim, S. G. E. H. Kim, C. J. Lafferty, and E. Dubovi. 2005. Coxiella burnetii in bulk tank milk samples, United States. Emerg. Infect. Dis. 11:619-621.

McCaughey, C., L. J. Murray, J. P. McKenna, F. D. Menzies, S. J. McCullough, H. J. O'Neill, D. E. Wyatt, C. R. Cardwell, and P. V. Coyle. 2010. Coxiella burnetii (Q fever) seroprevalence in cattle. Epidemiol. Infect. 138:21-27.

Muskens, J., E. van Engelen, C. van Maanen, C. Bartels, and T. J. Lam. 2011a. Prevalence of Coxiella burnetii infection in Dutch dairy herds based on testing bulk tank milk and individual samples by PCR and ELISA. Vet. Rec. 168:79.

Muskens, J., C. van Maanen, and M. H. Mars. 2011b. Dairy cows with metritis: Coxiella burnetii test results in uterine, blood and bulk milk samples. Vet. Microbiol. 147:186-189.

Muskens, J., W. Wouda, T. Bannisseht-Wijsmuller, and C. van Maanen. 2012. Prevalence of Coxiella burnetii infections in aborted fetuses and stillborn calves. Vet. Rec. 170:260.

Paul, S., J. F. Agger, B. Markussen, A. B. Christoffersen, and J. S. Agerholm. 2012. Factors associated with Coxiella burnetii antibody positivity in Danish dairy cows. Prev. Vet. Med. 107:57-64.

Piñero, A., J. F. Barandika, A. Hurtado, and A. L. Garcia-Perez. 2012 Evaluation of Coxiella burnetii status in dairy cattle herds with bulk-tank milk positive by ELISA and PCR. Transbound. Emerg. Dis. http://dx.doi.org/10.1111/tbed.12013.

Rodolakis, A., M. Berri, C. Hechard, C. Caudron, A. Souriau, C. C. Bodier, B. Blanchard, P. Camuset, P. Devillechaise, J. C. Natorp, J. P. Vadet, and N. Arricau-Bouvery. 2007. Comparison of Coxiella burnetii shedding in milk of dairy bovine, caprine, and ovine herds. J. Dairy Sci. 90:5352-5360.

Ruiz-Fons, F., I. Astobiza, J. F. Barandika, A. Hurtado, R. Atxaerandio, R. A. Juste, and A. L. García-Pérez. 2010. Seroepidemiological study of $\mathrm{Q}$ fever in domestic ruminants in semi-extensive grazing systems. BMC Vet. Res. 6:3.

Ryan, E. D., M. Kirby, D. M. Collins, R. Sayers, J. F. Mee, and T. Clegg. 2011. Prevalence of Coxiella burnetii (Q fever) antibodies in bovine serum and bulk-milk samples. Epidemiol. Infect. 139:1413-1417.

Taurel, A. F., R. Guatteo, A. Joly, H. Seegers, and F. Beaudeau. 2011. Seroprevalence of Q fever in naturally infected dairy cattle herds. Prev. Vet. Med. 101:51-57.

Tissot-Dupont, H., M. A. Amadei, M. Nezri, and D. Raoult. 2004. Wind in November, Q fever in December. Emerg. Infect. Dis. 10:1264-1269.

Tissot-Dupont, H., S. Torres, M. Nezri, and D. Raoult. 1999. Hyperendemic focus of $\mathrm{Q}$ fever related to sheep and wind. Am. J. Epidemiol. 150:67-74.

van der Hoek, W., J. Hunink, P. Vellema, and P. Droogers. 2011. Q fever in The Netherlands: The role of local environmental conditions. Int. J. Environ. Health Res. 21:441-451.

Willems, H., D. Thiele, R. Frolich-Ritter, and H. Krauss. 1994. Detection of Coxiella burnetii in cow's milk using the polymerase chain reaction (PCR). Zentralbl. Veterinarmed. B. 41:580-587.

Woldehiwet, Z. 2004. Q fever (coxiellosis): Epidemiology and pathogenesis. Res. Vet. Sci. 77:93-100. 